\title{
CARACTERÍSTICAS MORFOLÓGICAS DO CAPIM-ELEFANTE E CAPIM-BRAQUIARÃO SUBMETIDOS A DIFERENTES TAXAS DE LOTAÇÃO
}

\author{
Morphologic characteristics of elephantgrass and \\ braquiarãograss submitted to different stocking rates \\ Cláudia de Paula Rezende ${ }^{1}$, José Cardoso Pinto ${ }^{2}$, José Marques Pereira ${ }^{3}$, \\ Joel Augusto Muniz ${ }^{4}$, Ivo Francisco de Andrade ${ }^{2}$, Antônio Ricardo Evangelista ${ }^{2}$
}

\begin{abstract}
RESUMO
Objetivou-se com o presente trabalho avaliar algumas características das plantas forrageiras que podem ser utilizadas para determinar o fluxo de tecido vegetal que, associado ao conhecimento da dinâmica do perfilhamento, auxilia na determinação de práticas de manejo da pastagem, visando a maior rendimento forrageiro e produtividade animal. $\mathrm{O}$ experimento foi conduzido na Estação Experimental de Zootecnia do Extremo Sul da Bahia, da CEPLAC, localizada no município de Itabela-BA, com uma precipitação anual de $1311 \mathrm{~mm}$ e temperatura média de $25^{\circ} \mathrm{C}$, sem estação seca definida. $\mathrm{O}$ solo é um Ultisol com as seguintes características químicas médias: $\mathrm{pH}$ em H $\mathrm{H}_{2} \mathrm{O}=6,2 ; \mathrm{Al}=0,1 \mathrm{cmol}_{\mathrm{c}} / \mathrm{dm}^{3} ; \mathrm{Ca}=2,6 \mathrm{cmol}_{\mathrm{c}} / \mathrm{dm}^{3} ; \mathrm{Mg}=0,4 \mathrm{cmol}_{\mathrm{c}} / \mathrm{dm}^{3} ; \mathrm{K}=$ $0,2 \mathrm{cmol}_{\mathrm{c}} / \mathrm{dm}^{3} ; \mathrm{P}$ disponível $=2,9 \mathrm{mg} / \mathrm{dm}^{3}$. A área experimental foi constituída de 52 piquetes de Pennisetum purpureum cv. Cameroon e 52 de Brachiaria brizantha cv. Marandu, com uma área de $720 \mathrm{~m}^{2}$ cada um, totalizando $74.880 \mathrm{~m}^{2}$. A calagem e fertilização de estabelecimento foram efetuadas na base de $1000 \mathrm{~kg} / \mathrm{ha}$ de calcário dolomítico e $80 \mathrm{~kg} / \mathrm{ha}$ de $\mathrm{P}_{2} \mathrm{O}_{5}$. A adubação de manutenção foi aplicada na base de $160 \mathrm{~kg} / \mathrm{ha}$ de N, $60 \mathrm{~kg} / \mathrm{ha}$ de $\mathrm{P}_{2} \mathrm{O}_{5}$ e $120 \mathrm{~kg} / \mathrm{ha} \mathrm{de} \mathrm{K}_{2} \mathrm{O}$, parcelada em quatro aplicações. Cada gramínea foi submetida a quatro taxas de lotação, em um sistema de pastejo rotacionado com 3 dias de ocupação e 36 dias de descanso, resultando em um ciclo de pastejo de 39 dias. As taxas de lotação foram 3, 4, 5 e 6 novilhos/ha, com peso médio de $280 \mathrm{~kg}$. As taxas de lotação em $P$. purpureum cv. Cameroon afetaram significativamente a altura total de perfilhos, a altura do caule, a altura do meristema apical, os números de folhas completamente expandidas e emergentes e os comprimentos dessas duas categorias de folhas. Em B. brizantha cv. Marandu, as taxas de lotação afetaram as variáveis: altura total de perfilhos, altura de caule, comprimentos de folhas completamente expandidas e emergentes. Nas duas gramíneas, com o aumento das taxas de lotação, observou-se redução em todas as variáveis.
\end{abstract}

Termos para indexação: Altura de perfilhos, altura de meristema apical, Brachiaria brizantha, comprimento de folhas, folhas emergentes, folhas expandidas, Pennisetum purpureum.

\begin{abstract}
This work evaluated some forage plant characteristics that could be utilized to determine the vegetal tissue turnover that allied tillers dynamics support in practice pasture management, aiming highest forage and animal yields. The experiment was carried out in South Extreme Experimental Station of Animal Science (CEPLAC), situated in Itabela - BA. The annual rainfall at that place is $1311 \mathrm{~mm}$ and the mean temperature is $25^{\circ} \mathrm{C}$, without definite drought season. The soil is an Ultisol with the following values: $\mathrm{pH}$ in $\mathrm{H}_{2} \mathrm{O}=6.2 ; \mathrm{Al}=0.1 \mathrm{cmol}_{\mathrm{c}} / \mathrm{dm}^{3} ; \mathrm{Ca}=2.6 \mathrm{cmol}_{\mathrm{c}} / \mathrm{dm}^{3} ; \mathrm{Mg}=0.4 \mathrm{cmol}_{\mathrm{c}} / \mathrm{dm}^{3} ; \mathrm{K}=0.2 \mathrm{cmol}_{\mathrm{c}} / \mathrm{dm}^{3}$ and $\mathrm{P}$ available $=2.9$ $\mathrm{mg} / \mathrm{dm}^{3}$. The experimental area consisted of 52 paddocks of $P$. purpureum and 52 of B. brizantha with $720 \mathrm{~m}^{2}$ each. The liming of the soil and fertilization of establishement were made at $1000 \mathrm{~kg} / \mathrm{ha}$ of dolomitic limestone and $80 \mathrm{~kg} / \mathrm{ha}$ of $\mathrm{P}_{2} \mathrm{O}_{5}$ and the maintenance fertilization at $160 \mathrm{~kg} / \mathrm{ha}$ of $\mathrm{N}, 60 \mathrm{~kg} / \mathrm{ha}$ of $\mathrm{P}_{2} \mathrm{O}_{5}$ and $120 \mathrm{~kg} / \mathrm{ha}$ of $\mathrm{K}_{2} \mathrm{O}$. Each grass was submitted to four stocking rates, in a rotational grazing system with three days of occupation and 36 days of rest, which resulted in a grazing cycle of 39 days. The stocking rates were 3, 4, 5 and 6 steers/ha, with mean body weigth of $280 \mathrm{~kg}$. The stocking rates, in P. purpureum, affected significantly the tillers total height, stem height, apical meristem height, numbers of expanded completely and emergence leaves and the length of these two category of leaves. In B. brizantha the stocking rates affected the variables tillers total height, stem height, length of
\end{abstract}

(Recebido para publicação em 5 de maio de 2003 e aprovado em 15 de agosto de 2003)

\footnotetext{
1. Zootecnista - Aluna do curso de Doutorado da Universidade Federal de Lavras/UFLA - Departamento de Zootecnia/DZO - Caixa Postal 37 37200-000 - Lavras, MG - Pesquisadora da CEPLAC - Caixa Postal 07 - Km 22 Rodovia llhéus-Itabuna. cprrezende@zipmail.com.br

2. Engenheiro Agrônomo - Professor DSc da UFLA/DZO. josecard@ufla.br; iandrade@ufla.br; aricardo@ufla.br, Bolsistas do CNPq.

3. Engenheiro Agrônomo - Pesquisador DSc da CEPLAC. jmarques@cepec.gov.br

4. Engenheiro Agrônomo - Professor DSc da UFLA/DEX. joamuniz@ufla.br, Bolsista do CNPq.
} 
expanded completely and emergence leaves. With the increase of number of animals for unit of area (stocking rate) it was observed reduction in all the variables.

Index terms: Apical meristem height, Brachiaria brizantha, emergence leaves, expanded leaves, leaves length, Pennisetum purpureum, tillers height.

\section{INTRODUÇÃO}

Nos estudos de morfogênese, os registros de altura de perfilho e de meristema apical, o número e o comprimento das folhas por perfilho são parâmetros necessários para a determinação do fluxo de tecidos que, associados a estudos de dinâmica populacional de perfilhos, constituem ferramentas indispensáveis a serem utilizadas para melhorar práticas de manejo de pastagens.

No processo de alongamento do caule, o meristema apical é progressivamente elevado acima do nível do solo, tornando-se vulnerável à destruição pela desfolha. As conseqüências da elevação do meristema apical, decorrente do alongamento do caule, além de aumentar sua vulnerabilidade, reduz a relação folha/caule, e as folhas basilares entram em processo acelerado de maturação e senescência, contribuindo para a redução do valor nutritivo da forragem produzida (PINTO, 1993).

Segundo Alexandrino et al. (2000), uma das principais características das gramíneas forrageiras que garante a sua persistência após o corte ou pastejo é a capacidade de regeneração de tecido foliar, que ocorre a partir da emissão de folhas dos meristemas remanescentes ou das gemas axilares por meio do perfilhamento. Assim, fica evidente a importância do processo de perfilhamento quando o meristema apical é eliminado.

O número de folhas vivas expandidas por perfilho é razoavelmente constante dentro do genótipo, sendo dependente das condições do meio ambiente e do manejo. Daí, a razão de tal índice se prestar para definir a freqüência de corte ou pastejo das forrageiras, objetivando a maximização da eficiência de colheita, evitando-se, assim, perdas por senescência e morte (GOMIDE, 1997).

Objetivou-se com este trabalho avaliar a influência de diferentes taxas de lotação sobre algumas características morfológicas de Pennisetum purpureum Schum. cv. Cameroon e Brachiaria brizantha
(Hochst ex A. Rich.) Stapf cv. Marandu em pastejo rotacionado.

\section{MATERIAL E MÉTODOS}

O presente trabalho foi conduzido na Estação Experimental de Zootecnia do Extremo Sul (ESSUL), da CEPLAC, localizada em Itabela (16039'S e $39^{0} 30$ 'O), no extremo sul da Bahia. A área está sob o domínio do ecossistema de Mata Atlântica e o clima local é uma transição entre os tipos Af e Am, segundo a classificação de Köppen, com precipitação anual de $1311 \mathrm{~mm}$ e temperatura média de $25^{\circ} \mathrm{C}$, sem estação seca definida. O solo é um Ultisol (Typic Paleudult fine-loamy, kaolinitic, isohyperthermic), arenoso (>700 g de areia/kg) nos $20 \mathrm{~cm}$ superficiais, cujas características químicas médias por ocasião da implantação do experimento foram as seguintes: $\mathrm{pH}$ em $\mathrm{H}_{2} \mathrm{O}$ $=6,2 ; \mathrm{Al}=0,1 \mathrm{cmol}_{\mathrm{c}} / \mathrm{dm}^{3} ; \mathrm{Ca}=2,6 \mathrm{cmol}_{\mathrm{c}} / \mathrm{dm}^{3} ; \mathrm{Mg}=$ $0,4 \mathrm{cmol}_{\mathrm{c}} / \mathrm{dm}^{3} ; \mathrm{K}=0,2 \mathrm{cmol}_{\mathrm{c}} / \mathrm{dm}^{3} ; \mathrm{P}$ disponível = 2,9 $\mathrm{mg} / \mathrm{dm}^{3}$.

Os dados climáticos relativos ao período experimental foram obtidos na Estação Climatológica localizada na ESSUL (Figura 1).

A área experimental constou de 52 piquetes de Pennisetum purpureum cv. Cameroon e 52 de Brachiaria brizantha cv. Marandu, com área de $720 \mathrm{~m}^{2}$ cada um, totalizando $74.880 \mathrm{~m}^{2}$. No estabelecimento, os piquetes receberam $1000 \mathrm{~kg} / \mathrm{ha} \mathrm{de}$ calcário dolomítico e $80 \mathrm{~kg} / \mathrm{ha}$ de $\mathrm{P}_{2} \mathrm{O}_{5}$. A adubação de manutenção anual foi $160 \mathrm{~kg} / \mathrm{ha}$ de $\mathrm{N}, 60$ $\mathrm{kg} / \mathrm{ha}$ de $\mathrm{P}_{2} \mathrm{O}_{5}$ e $120 \mathrm{~kg} / \mathrm{ha}$ de $\mathrm{K}_{2} \mathrm{O}$, utilizando como fontes desses nutrientes os fertilizantes uréia, superfosfato simples e cloreto de potássio, respectivamente.

Cada gramínea foi submetida a quatro diferentes taxas de lotação, em um sistema de pastejo rotacionado com três dias de ocupação e 36 dias de descanso, resultando em um ciclo de pastejo de 39 dias. As taxas de lotação foram 3, 4, 5 e 6 novilhos/ha, com peso médio de $280 \mathrm{~kg}$. 


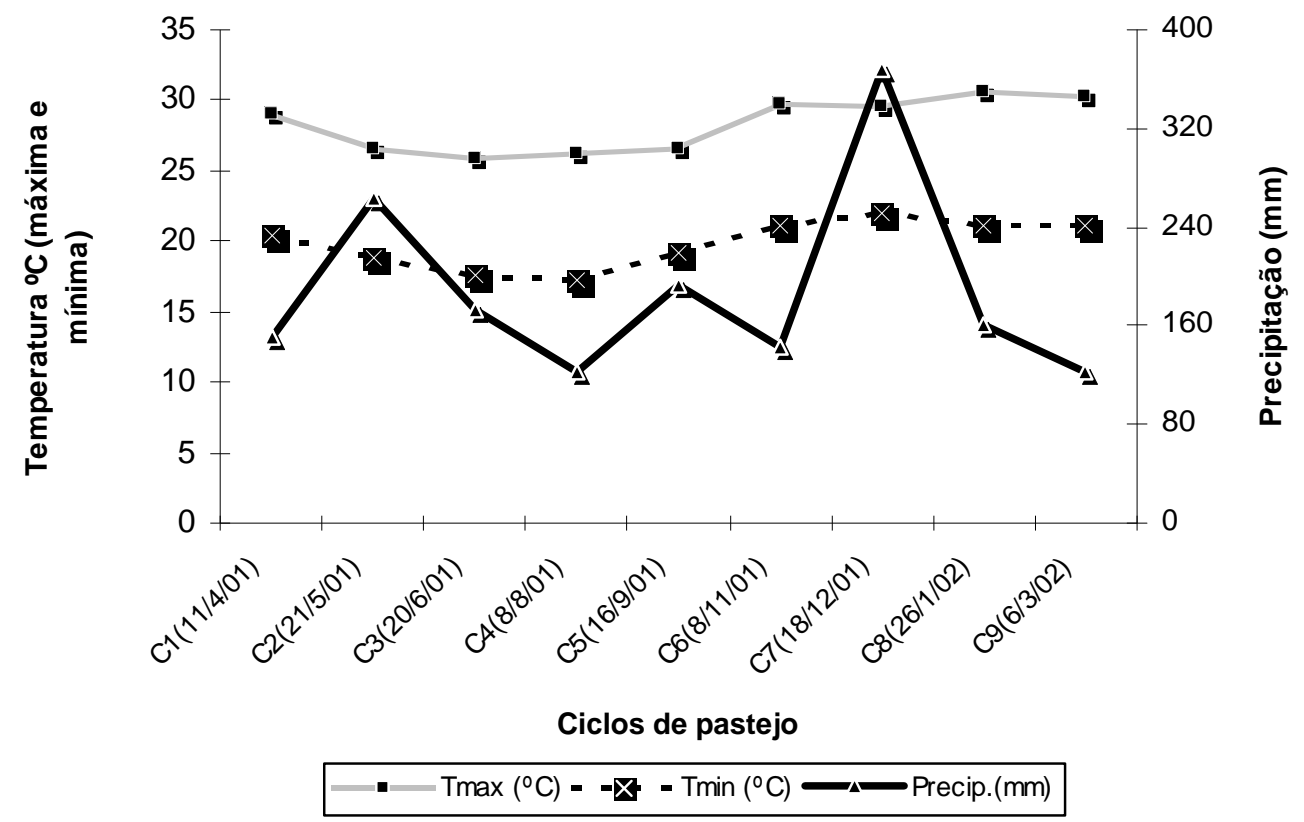

FIGURA 1 - Dados climáticos por ciclo de pastejo, no período experimental.

O experimento foi conduzido no período de verão, na região sul da Bahia, de abril a maio de 2001 e novembro de 2001 a março de 2002 (Figura 1).

Por ciclo de pastejo, escolheu-se aleatoriamente um piquete para cada gramínea e cada taxa de lotação, onde foram realizadas amostragens duas vezes por semana, quatro dias após a saída dos animais dos piquetes. Os perfilhos foram cortados rente ao solo e avaliaram-se 10 perfilhos basais de $P$. purpureum e 30 perfilhos basais de $B$. brizantha. No laboratório, foram efetuadas as seguintes medições:

- Altura total do perfilho - da base do caule até o ápice da última folha completamente expandida.

- Altura do caule - da base do caule até a lígula da última folha completamente expandida.

- Altura do meristema apical - pelo seccionamento vertical do caule, localizando o tecido meristemático. A medição foi realizada da base do caule até essa região meristemática.

- Número e comprimento das folhas completamente expandidas - folhas que apresentavam a lígula totalmente exposta.

- Número e comprimento das folhas emergentes - folhas que não exibiam a lígula exposta.
- Número de folhas senescentes - foram consideradas folhas senescentes as que apresentavam acima de $50 \%$ da área foliar senescida ou morta.

- Comprimento das folhas completamente expandidas.

- Comprimento das folhas emergentes.

\section{Análises Estatísticas}

Os tratamentos em estudo foram as quatro taxas de lotação em um delineamento em blocos ao acaso com repetição no tempo (ciclos de pastejo), segundo o modelo estatístico descrito abaixo:

$$
Y_{i j}=\mu+T_{i}+B_{j}+e_{(i j)}
$$

Sendo:

$\mathrm{Y}_{\mathrm{ij}}=$ Valor da observação da taxa de lotação i, no ciclo de pastejo j;

$\mu=$ Média geral (constante inerente a todas as observações);

$\mathrm{T}_{\mathrm{i}}=$ Efeito da taxa de lotação $\mathrm{i}$, sendo $\mathrm{i}=1$, 2, 3, 4;

$B_{j}=$ Efeito de bloco $\mathrm{j}$, sendo $\mathrm{j}=1,2,3,4,5$ e 6 .

$\mathrm{e}_{(\mathrm{ij})}=$ Erro experimental associado a Yij com distribuição normal, média 0 e variância $\sigma^{2}$.

Para atender às exigências desse modelo estatístico, admitiu-se que os efeitos dos fatores envolvidos no 
modelo foram aditivos, os tratamentos apresentavam variâncias homogêneas e os erros eram independentes com distribuição normal.

Os dados foram submetidos à análise de variância e teste de homogeneidade, sendo utilizado o procedimento ANOVA (para dados balanceados) do SAS INSTITUTE (1996). Nas análises de regressão, utilizou-se o pacote computacional SISVAR (FERREIRA, 1998).

\section{RESULTADOS E DISCUSÃO}

Em $P$. purpureum cv. Cameroon, observaram-se diferenças $(\mathrm{P}<0,01)$ em relação às taxas de lotação para altura total de perfilho, altura de caule, altura de meristema apical, número de folhas completamente expandidas, número de folhas emergentes, comprimento de folhas completamente expandidas e comprimento de folhas emergentes. A taxa de lotação de 3 novilhos/ha foi a que promoveu, no pasto, a maior altura total de perfilho, de caule e de meristema apical, maior número de folhas expandidas e emergentes, assim como maior comprimen- to geral das folhas expandidas e emergentes (Figuras 2 a 4). Isso ocorreu principalmente em função do menor número de novilhos por unidade de área, conseqüentemente, desfolhas menos severas, possibilitando que maior número de folhas do pasto escapasse do pastejo efetuado pelos novilhos. Nota-se que, com o aumento das taxas de lotação, ocorreu declínio gradual nas alturas, no número e no comprimento das folhas (Figuras 2 a 4). Com o incremento da desfolha, como conseqüência do aumento das taxas de lotação, a altura total do perfilho e a do meristema apical foram reduzidas em aproximadamente $28 \%$ e $24,7 \%$, respectivamente, enquanto a redução na altura do caule foi de $17,7 \%$.

Para os números de folhas completamente expandidas e emergentes, observa-se que as áreas submetidas às taxas de lotação de 3 e 5 novilhos/ha foram as que mantiveram maiores números de folhas, apresentando, respectivamente, 8,6 e 7,3 folhas completamente expandidas/perfilho, bem como 3,3 e 3,1 folhas emergentes/perfilho (Figura 3).

$$
\begin{array}{llll}
\hat{Y}_{\text {AT }}=197,08-15,11 X & * * & R^{2}=0,75 \\
\hat{Y}_{A C}=96,54-4,12 X & * * & R^{2}=0,46 \\
\hat{Y}_{\text {AM }}=78,62-4,71 X & * * & R^{2}=0,52
\end{array}
$$

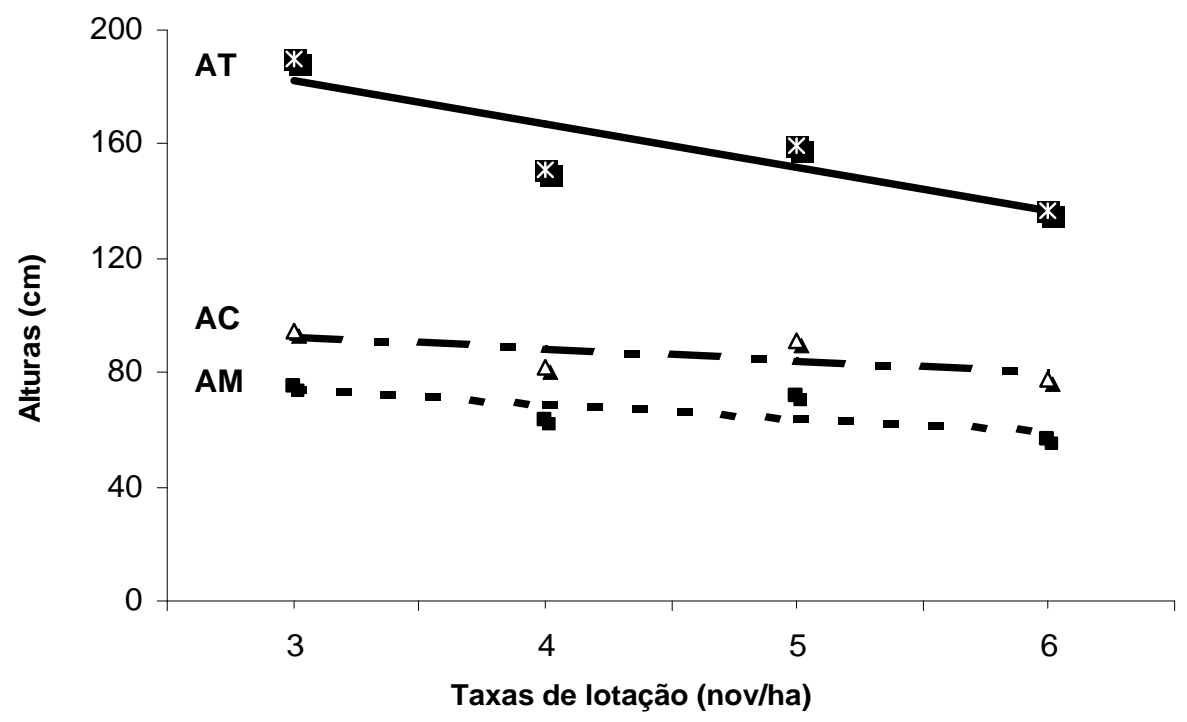

FIGURA 2 - Altura total de perfilhos (AT), de caule (AC) e de meristema apical (AM) de P. purpureum em função de taxas de lotação. 


$$
\begin{aligned}
& \hat{\mathrm{Y}}_{\mathrm{FEX}}=8,87-0,69 \mathrm{X} \quad * * \quad \mathrm{R}^{2}=0,66 \\
& \hat{Y}_{\mathrm{FEM}}=3,36-0,09 X \quad \text { ** } R^{2}=0,55
\end{aligned}
$$

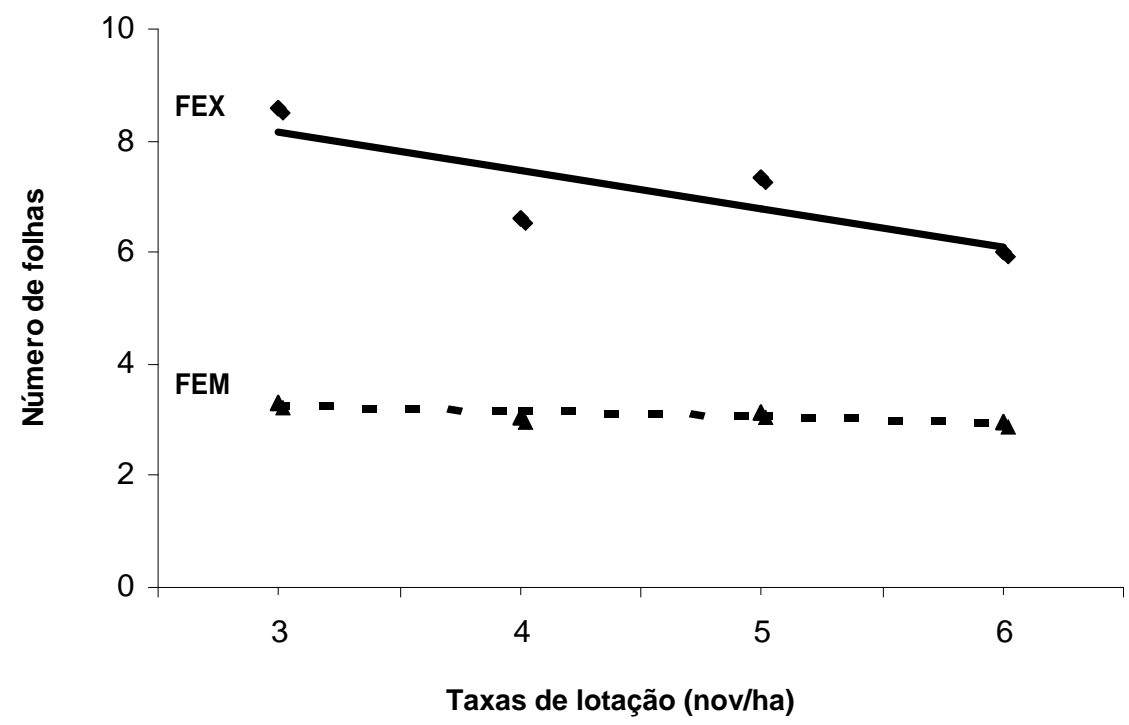

FIGURA 3 - Números de folhas completamente expandidas (FEX) e emergentes (FEM) de P. purpureum em função de taxas de lotação.

$$
\begin{array}{ll}
\hat{Y}_{\text {CEX }}=56,89-5,86 X^{* *} & R^{2}=0,93 \\
\hat{Y}_{\text {CEM }}=66,57-5,18 X^{* *} & R^{2}=0,89
\end{array}
$$

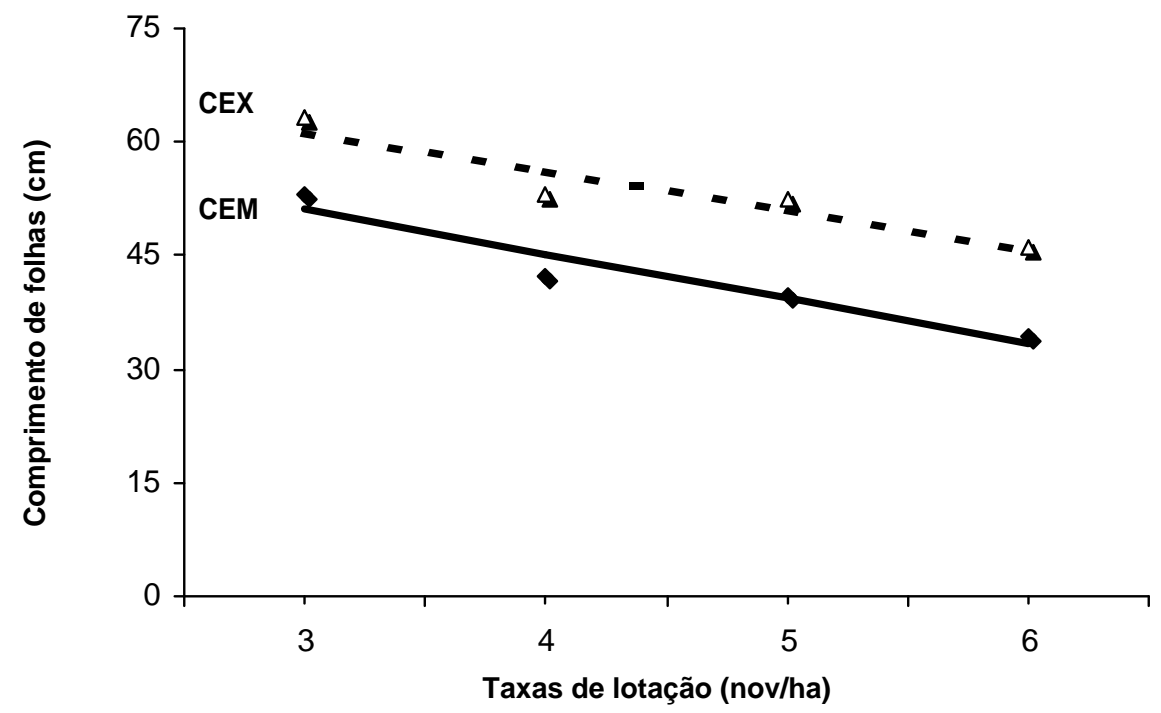

FIGURA 4 - Comprimentos de folhas completamente expandidas (CEX) e emergentes (CEM) de P. purpureum em função de taxas de lotação. 
No entanto, para número de folhas senescentes, não se observaram diferenças significativas entre as taxas de lotação, embora tenha se constatado a mesma tendência encontrada nas demais folhas, ficando a média em torno de 2,9 folhas senescidas/perfilho. Os comprimentos das folhas completamente expandidas e emergentes variaram de 34,3 a $52,9 \mathrm{~cm}$ e de 46,2 a 63,3 $\mathrm{cm}$, nas taxas de 6 e 3 novilhos/ha, respectivamente ( $\mathrm{Fi}$ gura 4).

O número médio de folhas emergentes foi de 3,1 folhas/perfilho e o número de folhas completamente expandidas foi de 7,1 folhas/perfilho. Em número, as folhas emergentes foram inferiores às completamente expandidas; no entanto, com relação ao comprimento, os resultados foram opostos. Isso ocorreu por causa da remoção de parte das folhas completamente expandidas pelo animal no ato do pastejo realizado anteriormente. Pelo fato de as folhas serem os principais órgãos responsáveis pela fotossíntese, acredita-se que o tratamento com taxa de lotação menor, com maior número de folhas e folhas mais longas, resultou em maior atividade fotossintética. No entanto, nem sempre essas características são indicativas dessa atividade.

A redução da fotossíntese com a desfolha não é necessariamente proporcional à área foliar ou à biomassa removida, uma vez que ocorre modificação no microclima do pasto, associado a contribuições desiguais de folhas de diferentes idades (BRISKE e RICHARDS, 1995). Segundo Ludlow e Charles-Edwards (1980), as folhas maduras que originalmente são sombreadas e re- manescentes da desfolha anterior podem apresentar capacidade fotossintética reduzida. Parsons et al. (1983) destacaram que as taxas fotossintéticas do dossel são mais fortemente correlacionadas com o potencial para rebrota do que a fotossíntese de folhas individuais. A desfolha menos severa pode gerar um efeito positivo, caso essa desfolha seja acompanhada de remoção de folhas de plantas vizinhas, mantendo, assim, uma grande proporção de folhas jovens na planta após a desfolha.

Rosseto (2000) observou no início da rebrota do capim-elefante 'Guaçu' que não havia nenhuma folha senescida; no entanto, ao final da rebrota, o número de folhas senescidas já era de 2,8 folhas/perfilho. Esse aumento estava associado à quantidade de folhas remanescentes após o pastejo, que foi em torno de $25 \%$.

Em B. brizantha cv. Marandu, observaram-se, com relação às taxas de lotação, diferenças significativas para altura total de perfilho $(\mathrm{P}<0,01)$, altura de caule $(\mathrm{P}<0,05)$, comprimento de folhas completamente expandidas $(\mathrm{P}<0,05)$ e de folhas emergentes $(\mathrm{P}<0,01)$. Não se detectaram diferenças com relação às taxas de lotação para altura de meristema apical e os números de folhas completamente expandidas, emergentes e senescentes. As alturas e os comprimentos podem ter sido afetados pelas diferentes taxas de lotação em função da remoção dessas partes da planta pelo animal durante o pastejo. Com o aumento do número de animais por unidade de área, ocorreu uma redução na altura total de perfilhos, de caules e comprimentos das folhas expandidas e emergentes (Figuras 5 e 6).

$$
\begin{array}{llll}
\hat{Y}_{A T}=60,47-4,08 X & * * & R^{2}=0,90 \\
\hat{Y}_{A C}=36,03-2,18 X & * * & R^{2}=0,94
\end{array}
$$

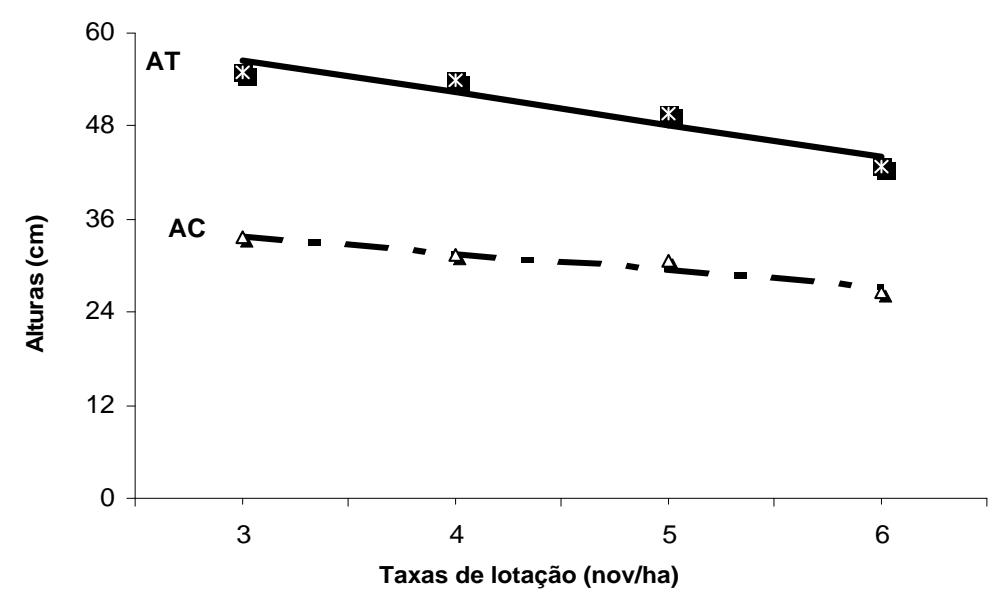

FIGURA 5 - Altura total de perfilhos (AT) e de caule (AC) de B. brizantha em função de taxas de lotação. 


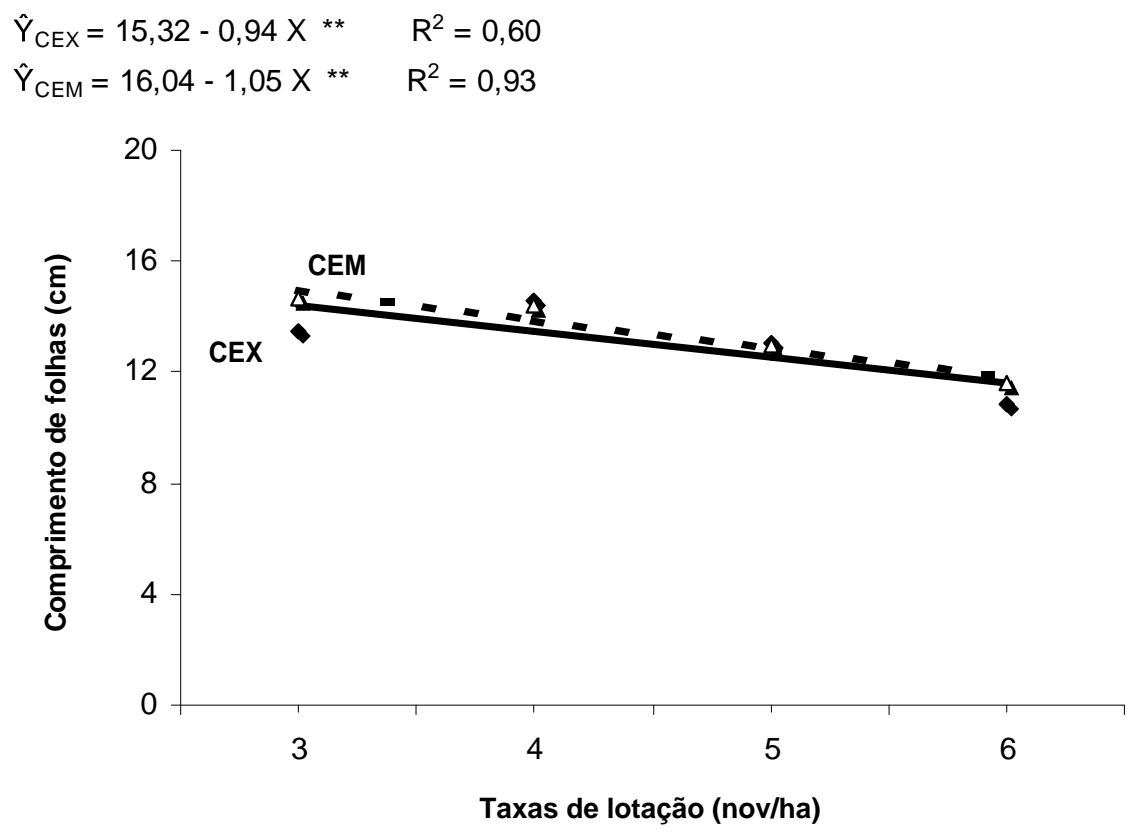

FIGURA 6 - Comprimentos de folhas completamente expandidas (CEX) e emergentes (CEM) de B. brizantha em função de taxas de lotação.

\section{CONCLUSÕES}

O aumento da intensidade de desfolha com o incremento das taxas de lotação promove redução na altura total de perfilho, altura de caule, altura de meristema apical, número e comprimento de folhas completamente expandidas e emergentes de Pennisetum purpureum cv. Cameroon.

Também em B. brizantha cv. Marandu, o aumento das taxas de lotação promove redução da altura total de perfilho, altura de caule, altura de meristema apical e comprimento das duas categorias de folhas.

A gramínea $P$. purpureum cv. Cameroon mostrase mais susceptível às desfolhas que a $B$. brizantha $\mathrm{cv}$. Marandu, principalmente tendo-se por base a altura do meristema apical.

\section{REFERÊNCIAS BIBLIOGRÁFICAS}

ALEXANDRINO, E.; NASCIMENTO JÚNIOR, D.; MOSQUIM, P. R.; REGAZZI, A. J.; FONSECA, D. M.; ROCHA, F. C. Efeito do tempo de rebrotação e de três doses de nitrogênio sobre as características estruturais da Brachiaria brizantha cv. Marandu. In: REUNIÃO ANUAL DA SOCIEDADE BRASILEIRA DE ZOOTENCIA, 37., 2000, Viçosa. Anais... Viçosa: UFV, 2000. CD-ROM.
BRISKE, D. D.; RICHARDS, J. Plant responses to defoliation: a physiologic, morphologic and demographic evaluation. In: BEDUNAH, J.; SOSEBEE, R. E. (Eds.). Wildland plants: physiological ecology and developmental morphology. Denver: Society for Range Management, 1995. p. 635-709.

FERREIRA, D. F. Sistema de análise estatística para dados balanceados SISVAR. Lavras: UFLA/DEX, 1998.

GOMIDE, J. A. Morfogênese e análise de crescimento de gramíneas tropicais. In: SIMPÓSIO INTERNACIONAL SOBRE PRODUÇÃO ANIMAL EM PASTEJO, 1997, Viçosa. Anais... Viçosa: UFV, 1997. p. 411-429.

LUDLOW, M. M.; CHARLES-EDWARDS, D. A. Analysis of the regrowth of a tropical grasslegume sward subjected to different frequencies and intensities of defoliation. Australian Journal of Agricultural Research, Colligwood, v. 31, n. 4, p. 673-692, 1980.

PARSONS, A. J.; LEAFE, E. F.; COLLET, B.; STILES, $\mathrm{W}$. The physiology of grass production under grazing. I. Characteristics of leaf and canopy photosynthesis of 
continuously grazed swards. Journal of Apllied Ecology, Oxford, v. 20, n. 1, p. 117-126, Mar. 1983.

PINTO, J. C. Crescimento e desenvolvimento de Andropogon gayanus Kunth, Panicum maximum Jacq e Setaria anceps Stapf ex Massey cultivadas em vasos, sob diferentes doses de nitrogênio. 1993. $149 \mathrm{f}$ Tese (Doutorado em Zootecnia) - Universidade Federal de Viçosa, Viçosa, 1993.
ROSSETO, F. A. A. Desempenho agronômico de pastagens de capim elefante cv. Guaçu (Pennisetum purpureum Schum.) e capim Tanzânia (Panicum maximum Jacq.) em sistemas de produção de leite. 2000. 144 f. Dissertação (Mestrado em Ciência Animal e Pastagem) - Escola Superior de Agricultura Luiz de Queiroz, Piracicaba, 2000.

SAS INSTITUTE. Users guide: statistics 1989-1996: version 6.11 System for Windows. Cary, 1996. 